\title{
Diana Kucherenko
}

\section{The Human Factor As a Basis of Evolutionary Development}

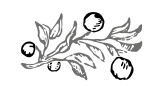

\section{Summary}

This paper is an analysis of the modern trends in the development of human capital and its influence on the evolution of society. There is a growing competition in the labour market today, and this paper considers factors influencing changes in the positions of different countries.

Journal of Economic Literature (JEL) codes: J24, J21, D8, J6

Keywords: international labour market, internal labour market, international education, academic mobility, knowledge economy, human capital

The early 21 st century is characterized by fundamental changes in scientific and technological progress, which drastically change the priorities in the development of society in all spheres. Technological innovations lead to a revolutionary breakthrough in the efficiency and productivity of labour, triggering fast development in the society, new requirements for training and specialist competence, and posing fundamentally new social challenges.

This fast change is above all qualitative. The industries that determine development are fundamentally different from those of even the late 20th century. Electronics, programming, computer modelling, neuroinformatics, laser technology, nuclear and other energy, electron-ion-plasma technologies, new materials, nanotechnologies, biotechnology, living systems, modern transport, building technologies, energy, ecology are relevant.

Diana Kucherenko, PhD in Economics, Associate Professor, Ukrainian State Employment Service Training Institute. 
At the current stage of social development, the common means of labour (or conditions necessary for the implementation of the labour process) act as civilization networks, in other words, as social and economic infrastructure connecting people to processes, opportunities and spaces. Traditional civilization networks include roads, transport, heating, water supply, sewage, housing, buildings, fiber optic networks, logistics networks, machinery, industry, etc. The new civilization networks are the Internet, information and communication technologies, modern education and systems of knowledge transfer and innovative environments.

The relationship between productive forces and civilization networks is expressed by the following formula: up to a certain level of complexity, the development of productive forces is provided by ordinary civilization networks, and above that, the productive forces characterizing new technologies can develop only on the basis of subtle civilization networks. There is a limit: thin civilization networks are impossible at a low level of development of conventional networks.

The means of labour are increasingly moving away from material objects, through which the processing of objects of labour is carried out. The modern trends in the development of means of labour are related to their movement towards internal, individual competences, knowledge, motivations and values. Thus today humans have the ability to be the carrying medium of modern productive forces, and thus it is impossible to alienate the means of production from their carrier. This dependence is a specific feature of the current level of development in these forces. The next feature of the current level of development of productive forces is that while land, buildings and equipment, as a means of labour, can exist separately from the worker, knowledge, competence, experience, communication, skill, motivation, value, as means of labour, do not exist on their own.

The specificity of modern productive forces includes two elements:

- The means of production of new technologies and innovations (knowledge, skills, competences, motivation, values) can not be separated from their carrier.

- The modern means of production are created by means of thin civilization networks (systems of knowledge, competences, values, modern education, innovative environments).

This specificity sets the trend in national economic development, namely: subtle civilization networks are the necessary condition for the technological modernization of the economy. It defines the requirement that the national innovation system should correspond to modern, subtle civilization networks, promote their development and contain particular forms of social relations in which it is possible to use the means of production inseparable from a person.

The principle of the new society was evidenced at the Intel Developer Forum (2016), where the heads of two technical giants, the Director General of General Electric, Jeff Immelt and the CEO of Intel, Brian Krzanich spoke of their plans to make cities smarter. Smart cities will collect and process an increasing amount of data. For this purpose, a growing Internet network of things and mobile devices will be used. By 2020, everybody will use up to 1.5 gigabytes of data per day. Hospitals equipped with 
basic smart technologies will use 3,000 GB per day. A smart plant will consume up to 1 million gigabytes. ${ }^{1}$

It is clear that the creation of modern technology has reached a level of complexity that requires considerably higher quality labour (to perform specific operations with a certain intensity). Creative thinking skills, self-organizing, a wide range of knowledge, motivation to learn and continuously improve, and the ability to find talented solutions in a teamwork are required from those working in the field of innovation. These abilities cannot be managed using the instructions and production technologies. Moreover, these abilities become the main means of production in the field of high technology today.

In the 2016 annual Global Innovation Index, the Ukraine ranks 56th of 128 countries. For the sixth time in a row, Switzerland is No. 1 in the rating, followed by Sweden, the United Kingdom, the United States and Finland. In Europe, the Ukraine ranked 34th of 39 countries, ahead of Macedonia (58), Serbia (65), Belarus (79), Bosnia and Herzegovina (87) and Albania (92) (Kucherenko-Martyniuk, 2011).

Unfortunately, insufficient action is taken to develop a national innovation system in the Ukraine, although efforts are made. Strong indicators in the Global Index of innovations for the Ukraine include "Training costs" (18), "Reaching Higher Education" (10) "The ease of obtaining credit" (18) "The number of patent applications" received by the national patent office (19), and the "Total cost of computer software" (20). It should be noted that our country ranks first in the world by the "Number of applications for utility models". The Ukraine is ranked fourth by the indicator "Employed women with a scientific degree". ${ }^{2}$

Strong indicators are effective stimulating factors and, despite the existing barriers, contribute to the development of an innovative environment.

What is the innovation environment? Firstly, it is a community of persons who implement complex projects, ideas, find original solutions, and work with the same people in creative groups. These people are the carriers of another type of thinking, namely entrepreneurial, research, and innovative. According to Tim Cook, CEO of Apple, the company does not buy startups to increase profits, but in search of talented people. When they find outstanding intellectual property, they buy it: actually, the company acquired 80 startups in the past 28 years and uses their potential to implement new technologies, improve services, and attract strong team members into their team.

Secondly, the integrated space is territorial, educational, communication, design, ideological and related to research. In such a space, horizontal bonds prevail, creating an opportunity for the high mobility of its participants, as the latter enables the flow of new ideas and the intensity of information exchange, and it is a particularly important condition of creating a supportive atmosphere for entrepreneurship. In addition, a community member's productivity exceeds that of a regular hired worker several tens of times due to the integrated space and lifestyle.

When there is such a space with such a community of people, various economic agents begin to be attracted to it, and the institutes necessary for effective productive forces begin to appear. Thus, people united by the common values and motives of 
developing a single cultural space create an innovative environment, i.e. social relations that meet the requirements of the modern development of productive forces (in other words, this is the national innovation system).

Recent research on the development of innovation in individual countries and all over the world suggests that this process is nonlinear, spontaneous, and multifactorial. The main feature is that its implementation requires the involvement of modern scientific achievements and educated workers. This feature determines the main trends in training, advanced training and retraining.

The issue of modern education is complex and multifaceted. Higher education occupies a special place in ensuring development in the post-industrial economy. After all, it is an employee required to have a certain high level of knowledge, expertise and skills that can only be achieved through an effective educational system, creates innovation.

New economic conditions require educational establishments (education) and leading companies (businesses) to find as much as possible the "intersection", to establish effective cooperation, implement joint projects in production training. Higher educational institutions should be guided by the introduction of standards and methodologies for so-called business education, when the main educational load is built on the acquisition of knowledge and skills that can be used to solve specific production (business, technological, etc.) problems.

The modern world is fully automated. Taking into account the time requirements in 2016, the Ministry of Economy of the Ukraine increased the public order for programmers and IT specialists. In addition, the number of vacancies for engineering, namely, technical specialties increased. ${ }^{3}$ This trend testifies to the attempts of national classical education to meet the challenges of time.

In a post-industrial economy, a new phenomenon - a powerful system of corporate education - is spreading. As large companies usually act as agents of the global innovation system, they must promptly respond to the challenges of the competitive environment, in particular regarding the training and re-training of employees. After all, the management of such companies cannot wait until "traditional education" understands the challenge and is rebuilt in accordance with the requirements of the time (this may take years, taking into account the time of study at the university). Under modern conditions, the leading companies are compelled to take care of the development of corporate systems for production training in response to requests of a specific company or even its divisions.

Undoubtedly, certain companies, especially large and well-known ones, invest in the creation of corporate education, but this is clearly only one of the methods of improving employees' professional skills, as such programmes cannot completely replace the system of fundamental education. The concepts of norms, rules and standards established by companies are formed in the system of professional education. In the post-industrial economy, interdependence between business and education leads to an understanding of effective vocational education (even outside the corporate sector) as an important element in improving corporate values. 
The modern concept of development only distinguishes innovations connected to the upgrading of education, including internal content, functions and the transformation into something new. Moreover, in cases of development, we are talking about growing, deployed in time and managed qualitative transformation in the content of education and educational activities (values, goals, systems, process, and result). The cumulative nature of development is the accumulation of purposeful changes in numerical and non-numerical values of the relevant features, and it promotes the introduction of innovation in education and the regular formation of a new organizational level in the educational process, includng quality improvement for the education and communication culture of teachers and students, the development of library and information services for students, the application of new pedagogical principles and high technology training etc.

Thus, in order to boost the creation of an innovative environment, the processes of development and improvement of these components in the framework of organizational, infrastructure, investment-related and legal support, technological commercialization, scientific and regulatory support, understanding the role of the human factor and improving the human resources management system at the macro level are relevant today in the Ukraine. At the micro level, staff management must take into account the requirements of time, and makes to review and completely change that the old paradigms of the relationship between employers, managers of different levels and employees now.

The most important features in the modern process of improving staff management is the creation of trust at the enterprise, which leads to the expansion of the executive powers of the employee on the spot, the promotion of dissent, decentralization and differentiation, allows change in the forms of control, namely, narrowing and substitution. The joint approval of business decisions contributes to a comprehensive vision of problems and to a holistic approach to the human potential in conjunction with strategic enterprise settings. The atmosphere of mutual trust creates a corporate culture of the innovative type, which is an integral part of the modern process of staff management.

A decisive factor in the socio-economic development of society is also the modern stage of scientific and technological progress, which accelerates not only its movement, but also fundamentally changes the world space, worldview of mankind, traditional productive forces and productive attitudes, deeply influences the human factor, organization of work, etc.

An important component of the contemporary economy is computer and information technology. The efficient use of information allows the maximization of efficiency in production, where the main factors are automation and communication. Today, electronics, programming, computer simulation, neuroinformatics, laser technology, nuclear and power engineering, electron-ion-plasma technologies, new materials, nanotechnologies, biotechnology, living systems, modern transport, building technologies, energy, ecology, etc. are necessary for innovation and investment development (Gray, 2016). 
According to the forecast of the World Economic Forum in Davos (2016), the Fourth Industrial Revolution will affect the labour market. A radical change will take place in professions in the next 5 years, and the skills that have been demanded by the market for decades are obsolete. According to the estimates, about $35 \%$ of the current skills will have changed by 2020 . More than $47 \%$ of the jobs will be automated. In the next 5 years jobs unkown today will become regular. ${ }^{4}$

The 2016 Davos World Economic Forum identified the main requirements that would affect employment, professional skills and staff recruitments in various sectors and regions. ${ }^{5}$ The capability to find integrated multi-level solutions to problems, requiring a wide outlook, professional knowledge and atypical thinking, is in the first place. Critical thinking, which allows a person to question the existing rules and change the circumstances was ranked second. Creativity in the broadest sense, which allows a non-standard approach to anything, and, most importantly, to see things that do not yet exist is another significant factor. The team approach in the organization of work requires the ability to manage people, because small creative and production teams will be created for solving operational tasks requiring both communicative and emotional intelligence. There is a need for the ability to form original thoughts, make decisions and bear responsibility. In today's fast-changing world, it is important to switch between different problems instantly and to consider several tasks simultaneously, and this ability is called cognitive flexibility.

According to experts, the current stage of technological revolution, information, information technology and the beginning of the information and electronic revolution has begun in the historically specific terms.

The reason for this revolution is that modern industrial technologies are fundamentally changed by computer-information technologies, biotechnology, artificial intelligence, 3D printers, living systems, etc. All these are united and there are completely new spearhead technologies, but society is not always ready to receive them and the attitude is not always adequate. This is a complex, contradictory, currently still insufficiently defined way of social development. We must understand that the process of the human society's transition to the new stage of civilization development has begun.

Modern spearhead technologies are the evidence of fundamental changes in the development of productive forces, because they are based on radically different principles of the functioning of production. These principles, including those related to the fact that new technologies simulate the actions of the human brain in a particular way (computer technology, robotics, neuroinformatics) along with the phenomena and actions of nature (biotechnology, living systems), and this fundamentally changes the understanding of the man's role in the world.

Spearhead technologies permit to change the attitude completely towards such indicators as labour productivity, labour-intensive production. As workers are almost insignificant in enterprises using such technologies, productivity is increasing tenfold. Accordingly, the labour intensity of products is decreasing fast, while the indicator of knowledge-intensity increases in the products, which requires the employees a certain amount of modern professional knowledge and constant self-improvement 
in addition to professional skill and an attitude of respect to the modern expensive equipment. In addition, these technologies significantly reduce the production cycle, because they work in the $24 / 7$ mode at the maximum speed, reducing production cost and significantly improving quality.

Spearhead technologies based on biotechnological, electro-ion-plasma and other processes are now machineless. They enable quick adaptation to the requirements and to continuous changes, which is an important characteristic, as it allows the quick recognition of the needs of both production and people. Since reconfiguration is incorporated in the programme of modern production, it can be carried out promptly, depending on requirements, almost instantaneously, saving significant time and allowing the company to lead the market, releasing small lots of competitive products.

Importantly, spearhead technologies are implemented in a resource-efficient way (based on the use of synthetic and composite materials); are environment friendly (closed production cycles with the recycling of industrial waste, wastewater treatment); are reliably controlled in order to achieve the desired quality of products based on the application of electronic achievements; and require a minimum amount of live labour, due to the complex automation using robotic complexes, rotor lines, flexible production systems, modern transport, energy, where the employees' functions are only to control and adjust the operation of automatic systems. The main workplace is a controller with programming skills and a detailed understanding of the complete algorithm for the entire process.

High technology dramatically changes the production process, and most importantly, the place of a human in it, because the principle affects and changes productive attitudes. Certain features characterize these technologies. If they are based on processes, then such technologies are almost machineless. From the perspective of the latest technology, a real human release of the process of direct production is under way, and an essentially "deserted" technology is formed. An enterprise with such technologies should be considered as a self-organizing system, which quickly responds to external changes, makes the necessary calculations, requests the needed or the system adjusts itself, does not require human labour, retraining of specialists, therefore, the re-adjustment takes place in the shortest terms, which gives a great saving for resources and time. Of course, a person who is released from the production process and is only required to have external control makes is the main impetus.

Such new technologies change the worldview, the whole philosophy of interconnections between the components of traditional production. This new paradigm changes the world as a whole, including the interconnection between the components in the production process: the objects and tools of labour, and live labour. Conscious or not, a person has a fundamental influence on the very essence of social and productive relations: the removal of live labour leads to the disappearance of a high number of traditional professions, the abandonment of professional knowledge, the release of workers, the shrinkage of the labour market, the increase of social instability etc.

Advancing development in the technological components in the modern production is driven by a desire to produce fundamentally new products of the highest 
quality at a minimum cost, to have time to implement these products while they are competitive and to make extra-high profits. This production process leads to the alienation of knowledge and information from their creators and carriers. The removal of live labour in the manufacturing sector is characterized by the loss of jobs, the loss of professional experience of the specialists, the growth of negativism to modern "humanless" technologies, the exacerbation of social tensions etc.

The external environment fundamentally changes the technological basis of the production process, and affects the internal structures of the social and production system. The robotisation of production regards the worker as an unpredictable and conflicting element of production that requires wage growth, increased social welfare costs, health insurance, training, retraining, advanced training etc. By the complete automation of production, live labour is eliminated and the process is completely intellectualized. The main content of labour today is its mental component, based on the corresponding amount of modern professional theoretical and computational knowledge.

One of the most important scientific and technological factor of innovation-oriented companies is the development of science and education. In addition to applied research and development, this also applies to fundamental research, and especially if undertaken by the state, which affects the competitiveness and productivity of a country. The conceptual system is a transformation of knowledge, knowledge, as basic information, which includes an innovative system received from the environment. This knowledge in the system is transformed into new knowledge.

Conclusions: Today, knowledge learnt in the education system is the basis for building an innovative economy. Economic factors characterize the efficiency and macroeconomic stability of a country, the functionality of all economic institutions. The EU's statistical reports show that the scientific and technical activities of private companies focus mainly on the creation of end products. The share of private capital - financing R\&D is $55 \%$ in the EU, and $67 \%$ in the US. The state's innovation policy is aimed at cooperation between the public sector, an active supplier of scientific and technical innovations, and the private sector, the user of innovative products created in the country.

The peculiarities of the formation of an innovative society in developed countries are accompanied by the emergence of economic and technological structures and elements, influenced by the trends of the new economy. The strategic direction of the transformation of the national economy is the development of an innovationoriented society, an increase in the innovative activity of business entities.

The development of innovation-oriented society is a prerequisite for achieving sustainable economic growth and high-quality life. The strategic development of an innovative society should include: the development and introduction of new competitive ICTs in all spheres of public life; provision of computer and information literacy; development of national innovation infrastructure; State support of new "electronic" and other sectors. 


\section{Diana Kucherenko: The Human Factor As a Basis of Evolutionary Development}

\section{Notes}

1 http://rusbase.com/story/intel-and-ge-about-smart-city/.

2 http://ain.ua/2016/08/16/664313.

3 http://ain.ua/2016/08/16/664406.

4 http://ain.ua/2016/08/16/664313.

5 http://ain.ua/2016/08/16/664406.

\section{REFERENCES}

Gray, Alex (2016): The 10 Skills You Need to Thrive in the Fourth Industrial Revolution. World Economic Forum, 19 January, www.weforum.org/agenda/2016/01/the-10-skills-you-need-to-thrive-in-the-fourth-industrial-revolution/.

Issue of the Cabinet of Ministers of Ukraine of June 17, 2009 No. 680 "On Approval of the Concept of the National System of Innovation Development”. http://zakon.rada.gov.ua/cgi-bin/laws/.

Issue of the Cabinet of Ministers of Ukraine dated 04.06.2015 No. 575 "On Approval of the Plan of Measures for the Implementation of the Concept of Reforming the State Policy in the Field of Innovation for 2015-2019". http://zakon5.rada.gov.ua/laws/show/575-2015-r/.

Kucherenko, Diana - Martyniuk, Olena (2011): Strategies of Educational Systems in the Countries of the World. IPK DSZU, Kiev.

Kucherenko, Diana G. - Martyniuk, Olena V. (2015): Actual trends of life-long education in Ukraine and EU. Modern Science - Moderni věda, No. 6, 43-49.

Schwab, Klaus (2017): The Fourth Industrial Revolution. Crown Business, New York. 